\title{
Third Gender Portrayal in Bollywood: An Analysis of Sadak
}

\author{
Toyeba Mushtaq, Dr. Aaliya Ahmed
}

Media Education Research Centre, University of Kashmir, Srinagar, India

\begin{abstract}
How to cite this paper: Toyeba Mushtaq | Dr. Aaliya Ahmed "Third Gender Portrayal in Bollywood: An Analysis of Sadak" Published in International Journal of Trend in Scientific Research and Development (ijtsrd), ISSN: 24566470, Volume-3 | Issue-3, April 2019, pp. 17-22. http://www.ijtsrd.co $\mathrm{m} /$ papers/ijtsrd216 36.pdf

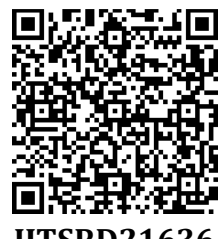
IJTSRD21636
\end{abstract}

Copyright (C) 2019 by author(s) and International Journal of Trend in Scientific Research and Development Journal. This is an Open Access article distributed under the terms of the Creative Commons

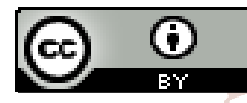
Attribution License (CC BY 4.0) (http://creativecommons.org/licenses/ by $/ 4.0$ )

\section{OVERVIEW:}

Gender identity has been in constant flux since the postmodern era. The postcolonial theorists, feminists and poststructuralists have challenged the rigidity of gender identity, subjectivity, and its representation from different angles. Thus, the term gender or sex has been in an endless conflict resulting into new perceptions from time to time. Third gender people have been a marginalized section in our society with identity deprivation and representation in the mainstream milieu. The term third gender is used for the people who transgress social gender norms. It is an umbrella term used for people who neither fall under feminine gender nor under masculine gender straightway. Hence their plight is more like the 'subaltern'.

Cinema constitutes the part and parcel of society. It works as a mirror in which human beings could see the reflection of their lives. Cinema has the power to influence more than any other art form. Therefore, it is very important to understand how a country, its people and its aspirations are represented in the cinema produced in the country. India is one of the countries that produce the most number of films in a year and has a large base of cinema-going public. Mainstream Hindi cinema is the most widely distributed cinema in India. Identity construction is one of the most significant issues in Bollywood. Without identity construction, one cannot survive. There are a lot of inconsistencies in our society and hence it is always in flux. It is an exigent task to build up and portray one's identity when the identity is of someone who doesn't fit into the mainstream society. Sexual minorities are slowly finding a place in Bollywood themes. Filmmakers in India are trying to step outside the beaten track of traditional Indian themes but there has been no or little allowance for the portrayal of the third gender, a subject that is still a taboo in a country where the discourse on sex itself is bound by moral restriction. The portrayal of their life stories and issues in Bollywood has veered between the sarcasm, denial, biased, comic, criminal and stereotyped. Their representation and construction in Bollywood are not free from the prevalent ideologies on gender where they are taken as the third category. They are studied and judged according to their sexual behavior. They are shown as oppressed solely due to their sexual orientation or gender orientation in India. Their social, political, economic and cultural exclusion has been the main cause of their plight. The third gender is an umbrella term used for LGBTTQQIIA+, which includes lesbian, gay, bisexual, transgender, transsexual, queer, questioning, intersex, intergender, asexual and the ' + ' at the end of the abbreviation is for fathomless sexuality.

The present research attempts to show the identity construction of a third gender by analyzing Sadak. The researcher tries to establish the fact that a fair treatment to the third gender is needed in order to deconstruct the myth of this marginalized section which deciphers their individual role and identity through the lens of sex only. 
The third gender falls under the category as neither a man nor a woman. The third gender refers to different people in different cultures, they may represent an intermediate state between women and men, a state of being both masculine and feminine, a state of being neither, a state where they cross dress and swap genders or state which is independent femininity and masculinity. Third gender people across cultures take up a particular gender with which they were not assigned at birth. The sight of third gender people especially transgender people speaks volumes about them in society. Wearing gaudy clothes and face covered with cheap and loud make-up, they roam in public places carelessly, trying to extract money from the public who generally give money to avoid them. They usually wear clothes that are very feminine and are identified by their prototypal clap (In Hindi teen talli).

\section{Third Gender in Indian Films}

The films representing the third gender usually fall into two categories: the art films that deal with the issues of the third gender seriously and are barely addressed to the Indian public, and the mainstream film industry that purely deals with it in terms of entertainment. The projection of the third gender community particularly hijras has always been stereotypical even when Bollywood is known to feed and mold the psychic construction of the audiences. While filmmakers are trying to step outside the clichéd themes, a majority of the third gender themes perpetuate worst stereotypes for cheap laughs in the country where the discourse of sex itself is still a taboo and is bound by moral restrictions of the society (Chatterjee, 2013). The last few years have witnessed a change in the role of the sexual minorities by breaking the moral shackles and creating tolerance towards the gender variant community. The aim of stereotypical portrayal is to gain accord of both those who are forming the discourse in Bollywood and those who are brought under the popular discourse because sexual discourse like any other discourse depends on acceptance and validation of the masses.

Subhan (2013) analyzes three different trends in Hindi film industry when it comes to portraying the third gender. Firstly, films that project the negative image of the third gender; secondly, films that deconstruct the existing dominant sexual discourse; and thirdly, films that highlight the conflict between the dominant and deconstructive sexual discourse which leads to debating of deconstruction versus reconstruction. Somehow their portrayal is decided by the society's prevalent ideology and identity discourse on the third gender. The third gender portrayal in mainstream Indian cinema has mostly boiled down to comic. Their reallife sufferings have always been faded to the main script of the film. Queer Film Festivals like Kashish: Mumbai International Queer Film Festival; Nigah Queer Fest, Delhi; Bangalore Queer Film Festival; Dialogues: Annual Kolkata Lesbian, Gay, Bisexual and Transgender Film and Video Festival and Lesbian and Gay Film Festival at Panjab University, Chandigarh play a very decisive role in taking queer cinema to queer audience as well as the mainstream audience.

Saxena P. (2011) writes that third gender characters in Bollywood have always been shown as a bunch of crude jokes and are generally portrayed as objects of mockery and denial. Eunuchs are usually portrayed as characters with loud makeup, hands clapping, gaudy sarees, singing, blessing or cursing in a hoarse voice. Indian cinema has a long tradition of having songs or funny scenes featuring crossdressing male characters like Rishi Kapoor in Rafoo Chakkar (1975) or Amitabh Bachchan as a eunuch in Laawaris (1981) and many films featuring hijras. Films like Andaz (1949) and Sangam (1964) had love triangles in their script where the real plot was about the friendship between the two male lead characters- the presence of a female character in such movies was just to reduce the homosexual angle. Bollywood opened its account on film portraying third gender people in late eighties. Gopinath G. (2008) in her research paper titled 'Queering Bollywood' writes that the character Pinku in Mast Kalander (1982) was an amalgam of a comic and villainous character. Even in Ramesh Sippy's Sholay (1975) also brought in an insignificant character as a jail inmate who makes passes at other men openly. Though the character isn't prominent but can't be overlooked and is observant enough. After the 1990s, gay sidekicks emerged as comic characters continuously in films like Hum Hain Rahi Pyaar Ke (1993), Raja Hindustani (1996) and Taal (1999). Then came films with complex and serious gay characters like Bombay Boys (1998) and Split Wide Open (1999). Sensitive and tense films like Sadak (1991), Bombay (1995), Tamanna (1997), Darmiyaan (1997), Shabnum Mausi (2005), Murder 2 (2011) portrayed hijras in prominent roles.

Chatterjee R. (2013) in her magazine article '100 Years of Indian Cinema: Homosexuals and the third gender on celluloid' writes that trying to break the stereotypical portrayal of the third gender people films like Rules- Pyar ka Superhit Formula (2003), Girlfriend (2004), Page 3 (2005), Life in a Metro (2007), Honeymoon Travels (2007) ended up in propagating the stereotypes which the filmmakers were trying to avoid. Mainstream cinema has disappointed the third gender issue in general. But at the same time, there are a number of films that are representing the cultural phenomena of the third gender seriously. Films among those were Tedhi Lakeer (2004), Teen Deewarein (2003), My Brother Nikhil (2006), Touch of Pink (2004), Stag (2001), Yours Emotionally (2006), Happy Hookers (2006), I Can't Think Straight (2007), Luck by Chance (2009). South filmmakers like Kaushik Ganguly, Sanjoy Nag, Sridhar Rangayan, Onir, and Rituparno Ghosh have immense contributions to this genre of films. Their films like The Pink Mirror (2006), Yours Emotionally (2007), 68 Pages, I AM (2007), Memories of March (2010), Aarekti Premer Galpo (2010), Chitrangada (2012) have been crucial to the case and were lauded at international film festivals.

Meanwhile, some of the mainstream Bollywood gay films have been nothing but just a spoof. Films like Dostana (2008) and Student of the Year (2012) introduced the concept of homosexuality but failed terribly to bring commiseration and serious on the issue. Consequently few films like Aligarh (2016), Bullet Raja (2013), Rajjo (2013), Raktdhar (2018) tend to break the stereotype and reform the roles of LGBT characters in the films.

\section{Film Synopsis (Sadak):}

This film is considered a revolution in the portrayal of the third gender in Bollywood, as the movie chose a Hijra as an antagonist rather over a masculine antagonist. Seeing a Hijra as an antagonist was something very new and shocking for the viewers of Hindi cinemas. The film was the second highest grossing Hindi film in the year 1991 and the seventh highest grossing Hindi film in the 1990s. The film is 
remembered for the award-winning performance by Sadashiv Amrapurkar as the film's antagonist. Sadashiv Amrapukar won Filmfare Award for Best Performance in a Negative Role in 1991 for the film. Sadak was inspired by the 1976 American film Taxi Driver. The film was so loved among the audience that the film was remade in Tamil as Appu directed by Vasanth.

The story revolves around Ravi (Sanjay Dutt) a taxi driver, who falls in love with Pooja (Pooja Bhatt), a woman forced into prostitution by an evil transgender known as Maharani (Sadashiv Amrapurkar). The film highlights the struggle of Ravi to rescue Pooja from the clenches of Maharani. 2019 will see a sequel of Sadak titled Sadak 2, starring Alia Bhatt and Aditya Roy Kapur in lead roles alongside with Pooja Bhatt and Sanjay Dutt in their original roles. The film is produced by Mukesh Bhatt and directed by Mahesh Bhatt.

\section{Multimodal Discourse Analysis of Maharani-The Antagonist: \\ Cinematography:}

A long establishing shot of Maharani is shown to introduce the character (Fig.1) creating a lot of visual space in the image. High key lighting is used near Maharani to highlight her character in the frame while the rest of the frame uses low light. Maharani is placed under The Rule of Thirds in the frame to balance the negative space around the frame. The curtains flutter in the establishing shot highlighting the ambiguity of the situation. Reaction shots are also used whenever Maharani is shown to highlight the fear, shock, and disgust people have when they see her (Fig.1.1 and 1.2).

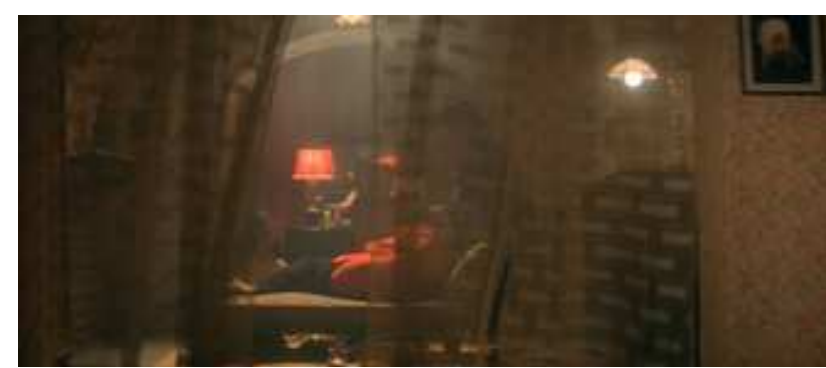

Fig.1

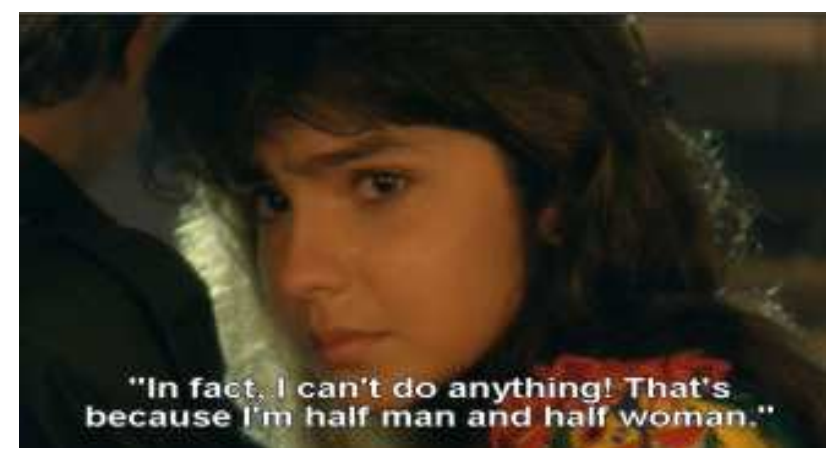

Fig.1.1

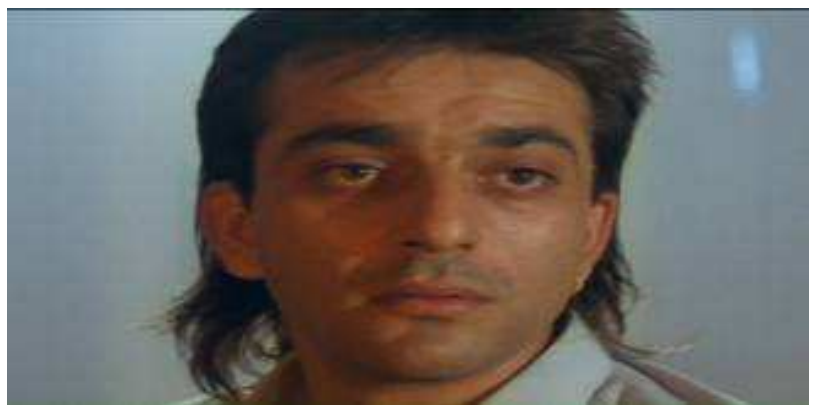

Fig.1.2
A lot of close up (CU) and extreme close shots (ECU) of Maharani are used in the film to capture the dark emotions shown on her face and the hand gestures. It is done throughout the film to exaggerate Maharani's facial expressions which convey how evil, ruthless and criminal she is. She holds a very shady and dark character in the film. For example, while putting a flick of hair in her mouth she tells Ravi to have sex with Pooja in front of her (Fig.1.3). Low angle shots are used whenever Maharani is shown with her prostitutes to symbolize Maharani's dominance over the prostitutes (Fig.1.4). Maharani is placed at the most important place in most of the shots. In most of the shots, the character is placed in such a way that she remains the centre of attention despite there being additional characters in the frame. The proximity between Maharani and other characters throughout the movie has been shown very close. Maharani in various scenes is shown to touch Pooja, Ravi, Gotya, Gullu inappropriately.

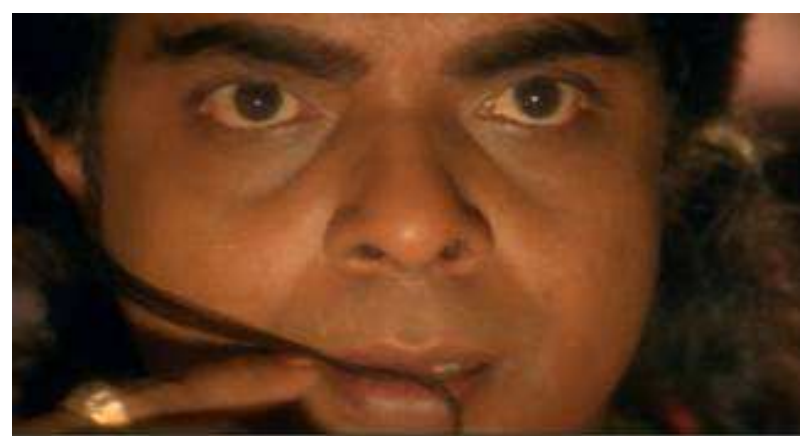

Fig.1.3

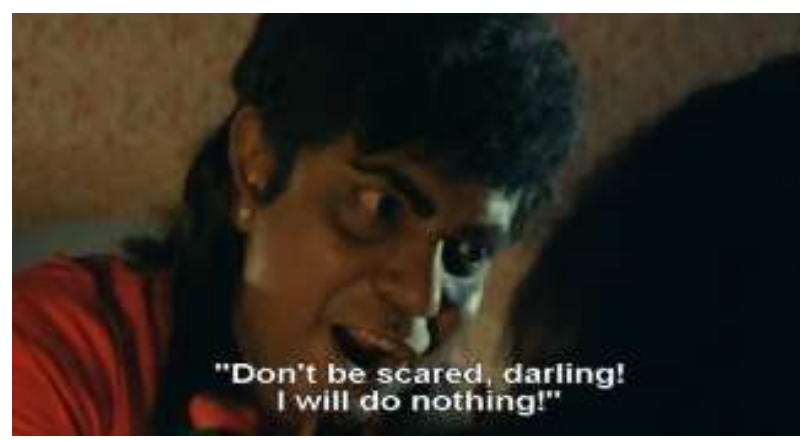

Fig.1.4

In the climax of the film when Ravi is beaten to death by Maharani and her henchmen, a point of view (POV) shot is taken from Ravi's point of view. The low angle POV shot creates empathy for Ravi and makes the character of Maharani look powerful and strong (Fig.1.5).

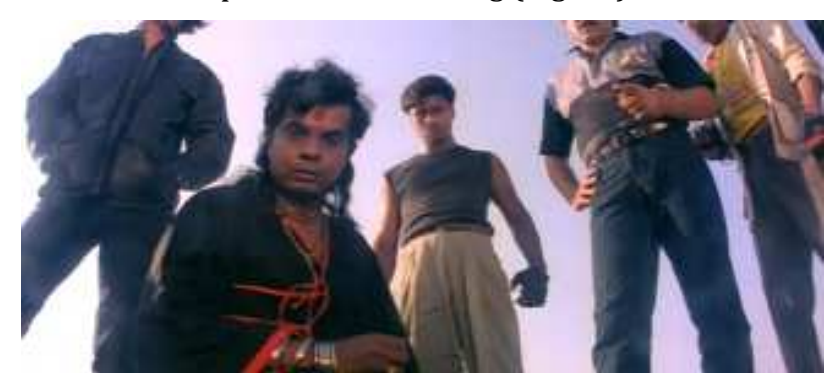

Fig.1.5

\section{Sound:}

Throughout the film, suspense music is played in the background whenever Maharani appears on the screen. The soundtrack is created to build tension and fear in the film. Kabhi aar kabhi paar laga teerai nazar is playing in the 
background music. The music and scene juxtaposition help in creating a new mood to the viewers. The suspense soundtrack right after playing Kabhi aar kabhi paar laga teerai nazar acts as a surprise, surprise that triggers uneasiness.

In the film, the third gender has been constructed as incapable of doing anything sexual and reinforcing the stereotype of beauty. In the first meeting with Pooja, Maharani tells her

'Kamal hai qudrat ka! Kya khoobsurati! Kya cheez banayi hai upar wale ne! Dekh dekh mere toh baal khade ho gaye haath pe, jaan hi nikal gayi meri! Oh, kya rang! Haye re yeh badan, aye haye!'

\section{Translated as:}

'Beautiful! A wonder of nature! I am wonder-struck! I am almost dead out of wonder! Such a fair skin... And a curvaceous body!

'Darr matt meri jaan, darr matt. Main kuch nahi karungi, main kuch kar hi nahi sakti. Janti ho kyun? Kyunki main aadha mard aur aadhi aurat hun. Dekh na, na roop na rang-dekh yeh kismat ka khal tog dekh (while clapping her hand-typical of a hijra). Agar kuch haina mere paas toh who hai dimag. Haan, kamal ka dimag hai mere paas. Isliye mardoun ke sewa karti hun aur auratoun ka danda. Yahan ka raja, is jism ke bazaar ka maharaja aur naam Maharani'.

\section{Translated as:}

Don't be scared, darling! I will do nothing! In fact, I can't do anything at all. That's because I am half man and half woman. I have neither looks nor glow; a cruel joke of destiny. All that I possess is a great brain. A great brain! No wonder I serve men and sell women. The king of the flesh trade and the name is 'Maharani'.

A scene in the film also highlights the ridicule transgender people face because of heterosexual people in the society. Trying to console pooja after capturing her, Maharani says to Pooja after hearing her sobs:

'Kya row rahi hai? Tamasha karti hai, che! Aai ladki! Row matt ladki, main bol deti hun. Kuch nahi hota rowne dhowne se! Apni Taqdeer nahi badalti, samjhi kya? Agar rowne dhowne se taqdeer toh main rowti, main nahi apni taqdeer badal leti? Main bhi bohat royi thi jab logoun ne mujhe namard kaha, hijra kaha! Lekin meri takdeer mein likha tha hijra banna toh main hijra ban gayi! Teri taqdeer mein hai randi banna toh tu randi banegi! Aur top ki randi banegi, bolti hun! Apne aap se samjhota kar le, nahi toh pashtaogi! Taqdeer se nahi khelna kabhi'.

\section{Translated as:}

What are you crying for and creating a fuss? Stop crying, girl! It won't change your destiny! Wouldn't I change my lot if it happened? I also cried a lot when people called me a Eunuch. But I was destined to be a Eunuch so I am one! You are destined to be a whore... and you will be one! A top one on that! I promise. Come to terms with yourself or you're going to regret it! Never play with your destiny.
The film also highlights the double face of the society in a scene. A customer, who has come to a brothel, tries to lecture Maharani about humanity. While bidding for Pooja from Ravi, a customer who already had bid for her says:

Yeh galat baat hai Maharani, us ladki ka suada hamare saath hua tha. Yeh insaniyat nahi hai, be-imani hai sarasar!

\section{Translated as:}

This is wrong Maharani, you have already committed this girl to me. This is no decency! This is cheating!

\section{To which Maharani replies:}

Aye, chal aye! Chal seth phut! Randi aur badhwoun ko insaan samjha kis ne jo humein insaniyat sikhayen, haan? Yeh le, yeh le - ja teri dukaan pe baith aur be-imani ka danda kar! Hamnein imandari matt sikha, chal phut!

\section{Translated as:}

Hey, get lost! When have pimps and whores ever been considered human that you are talking about decency? Here, take your money and go back to your shop where you preach humanity. Don't give us sermons about it... scram!

\section{Mise-en-scene:}

The visual representation of Maharani in the film is stereotypical. Clad in a saree, adorned in bangles, long hair sporting a big red bindi, the evil Maharani in Sadak is nothing like an average Bollywood antagonist. The first look is enough to send chills down the spine of the audience. Having crude gestures and shaving while wearing a saree surely made the character scary. The language Maharani uses in the film is very crude. She uses words like 'Aye, haye, haan, chal phut' symbolizing her unsophisticated nature. Maharani has been shown in the film as devoid of any human feeling. Maharani is doing a photo shoot while ignoring Pooja, who cries in a corner (Fig.2)

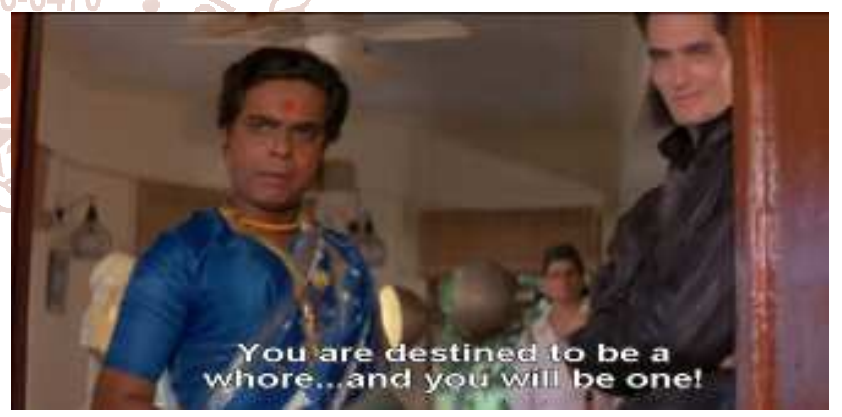

Fig.2

Maharani in (Fig.2) can be seen in a blue saree. This is the only shot in the film where she is dressed in a saree, with her hair pinned with flowers; make up done, wearing jewelry and fake breasts. Throughtout the film she is seen wearing a dress colored black and red through the movie, symbolizing power, evil, death, and dominance (Fig.2.1 and 2.2).

The film uses a lot of low key and chiaroscuro lighting in the frames shot in the brothel to create a visual drama between the figures and the space in the shots. Warm colors are used in the lighting of the brothel representing anger, violence, caution and warning. The orange and red lighting gives the audience a dreadful feeling of the place and the character. 


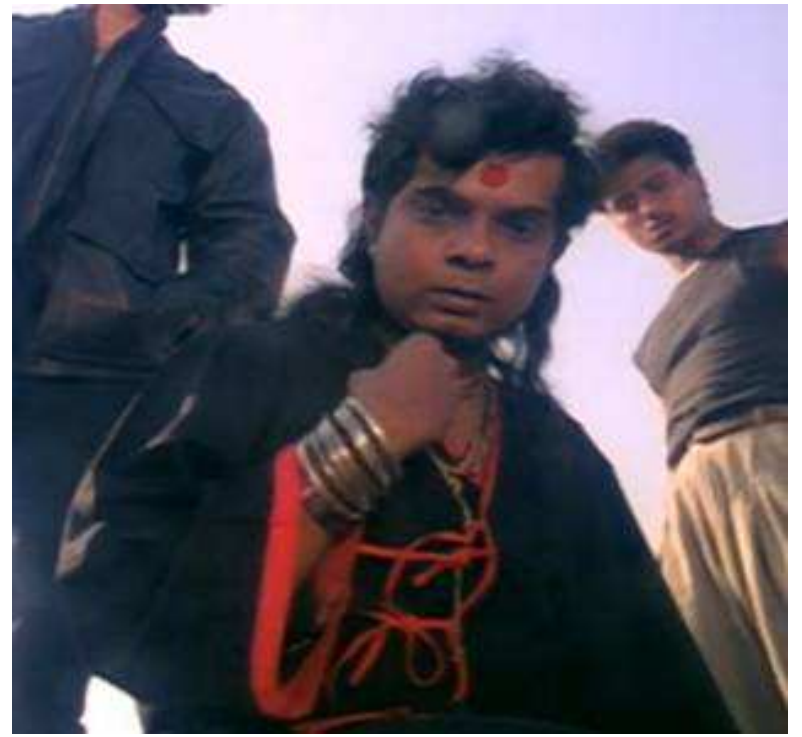

Fig.2.1

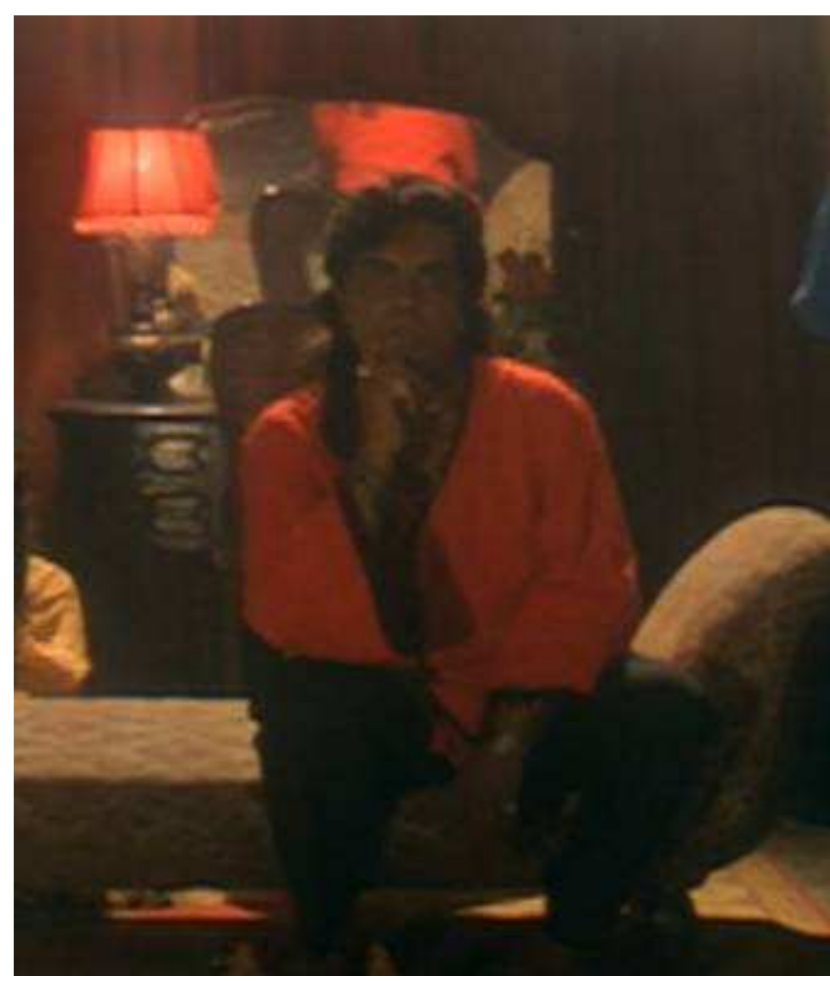

Fig 2.2

No doubt Sadak gave a lot of screen space to a transgender character but the film also justifies the negative representation of the third gender. Maharani as third gender poses a great threat to the heterosexual in the films thus evoking deep-rooted anger and hatred towards the third gender. The film shows heterosexuals as victims of the wrath of Maharani as a Eunuch. Her projection as inhumane and most of the heterosexual people as humane in the film further accelerates the justification of taking the third gender as the 'other'. This film also accentuates stereotype of other Hijras. In a scene with Maharani a group of Hijras are shown singing in their hoarse voices while clapping and dancing (Fig.2.3). The scene as such has no importance in the script but has been placed in the film to put an entertainment element in the film. The climax of the film shows Ravi burning Maharani in her brothel, symbolizing burning of the evil in Ramayana; where Hanuman burns Lanka to save Sita.

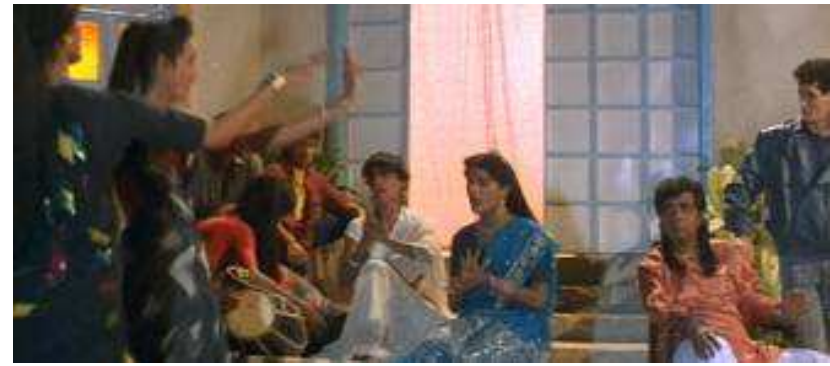

Fig.2.3

\section{Editing:}

The most common transition between the shots used in the film is a simple cut. The monotonous cuts have been put in between different shots and angles of the camera. Most of the cuts in the film have been accompanied by diegetic sound (dialogues and background music) and different camera shots. The cuts in the film change the shots in the film. Jump cuts are used to highlight the reactions shots between the characters of the film, for example, the scene that introduces Maharani to the viewers where she sees Pooja for the first time. Dissolve is used to join various shots in the film. Flashbacks are used in the film to stimulate Ravi's memory. Ravi's flashbacks of her sister are not located in the current storyline but are used on purpose to show the psychological depth of Ravi's character. Dissolve transition (Fig.3) is used in the sequence of flashbacks of Ravi. The shot has the faded out the close-up (CU) shot of pistol in Ravi's hand to a long shot (LS) of Ravi and his grandfather. The dissolve in the shot symbolizes overlapping of ideas in the two shots i.e. Ravi thinking of committing suicide because of haunting memories of her sister. 180-degree rule is applied in most of the shots of Maharani with other characters in the film to maintain the spatial relationship between the characters in different scene. Over the shoulder shots are usually used to make the scene more organized and draw a relation between every person on screen (Fig.3.1).

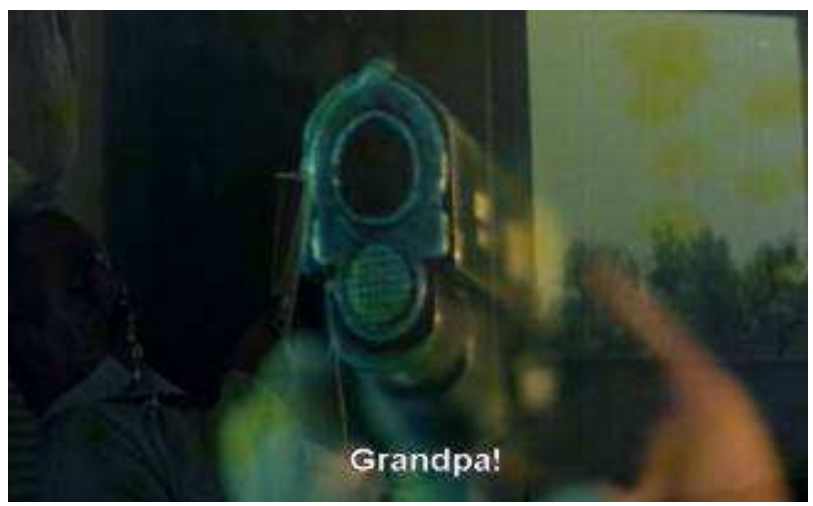

Fig. 3

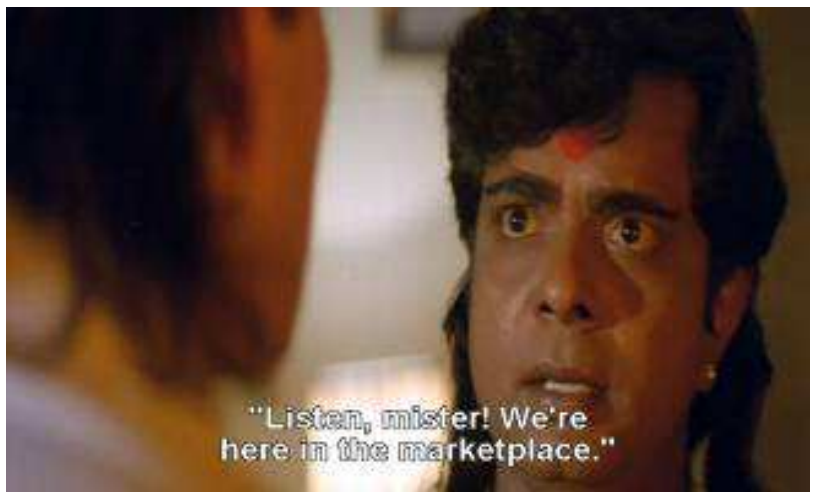

Fig 3.1 


\section{Conclusion:}

It is because of the control of heterosexual over nonheterosexual over the years that the dichotomous gender and the third gender have been represented in a typical colonial way in our society in order to make them culturally real. The status of the dichotomous gender is considered natural and desirable while as that of the gender variants are associated as unnatural and ostracized. It is the existence of myths like these that become the foundation of the dominance of one sex over the other. The body of the third gender is written and re-written from time to time by the dominant sex which leads them to lose control over their body and identity. In this whole process, the third gender falls into the marginalized and hence stereotyped treatment by the filmmakers (Foucault M. 1980a). Accordingly, since nineties, Bollywood has made films which give the third gender space and voice to speak out their tribulations primarily because of the existing discourse. This has directly leads to questioning the dominant sexual discourse. The plots of these films strongly reflect the demand of the third gender to fit in the cultural system of a society like the other two dominant sexes. This change in Bollywood strongly predicts social, economic, and cultural relationship with the third gender. Hindi film industry is a typical example of how power discourse demolishes the identity and individuality of the third sex. The inclusion of the third gender in the mainstream society acts as a threat to the power domination existing from ages in the society. The concept of the power of the dichotomous gender to crush the sexual minorities has been the central idea of some Bollywood films.

The film Sadak which was released in 1991 and directed by character of a transgender into an open and serious space. The film however, shows the transgender as an antagonist in the film thus sending a signal of negativity to the audience about the third gender. While analyzing the film it was seen that the projection of the villain was made dramatic and jarring. The lighting, dialogues, costumes, camera angles make the audience abhor the character. No doubt it was for the first time in Bollywood that a transgender character got a serious character in the film but the projection of the character throughout the film has been full of hatred and annoyance.

\section{References:}

[1] Chatterjee, R (2013). 100 Years of Indian Cinema: Homosexuals and the third gender on celluloid. Retrieved from http://ibnlive.in.com/news/100-yearsof-indian-cinema-homosexuals-and-the-third-genderon-celluloid/375374-8-66.html on $01 / 02 / 2018$ at 12:41 PM.

[2] Subhan, H. (2013). Tryst With Destiny: Sexual Discourse and Third Gender in Select Indian Bollywood Films. International Journal of Humanities and Social Science Invention 2 (7):34-42.

[3] Saxena. P. (2011). Life of a Eunuch. Shanta Publishing House. 131-135

[4] Gopinath, G. (2008). Queering Bollywood. Journal of Homosexuality. $\quad 39$ : $\quad 3-4, \quad 283-297$, DOI: $10.1300 / J 082 v 39 n 03 \_13$

[5] Foucault, M. (1980a), 'Two lectures', in C. Gordon (ed.), Power/Knowledge, Brighton: Harvester: 80-105. Mahesh Bhatt is one the earliest films which brings the

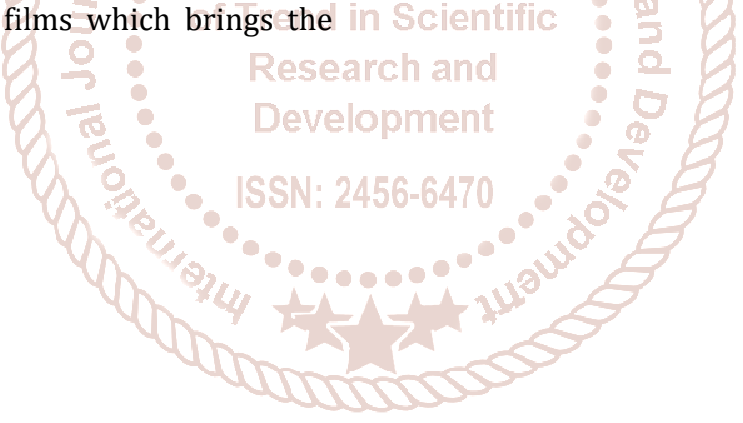

